\title{
The Frizzled 3 gene is associated with methamphetamine psychosis
} in the Japanese population Makiko Kishimoto ${ }^{1}$, Hiroshi Ujike* ${ }^{* 1,2}$, Yuko Okahisa ${ }^{1}$, Tatsuya Kotaka ${ }^{1}$, Manabu Takaki ${ }^{1}$, Masafumi Kodama ${ }^{1}$, Toshiya Inada ${ }^{2,3}$, Mitsuhiko Yamada ${ }^{2,4}$, Naohisa Uchimura ${ }^{2,5}$, Nakao Iwata ${ }^{2,6}$, Ichiro Sora ${ }^{2,7}$, Masaomi Iyo ${ }^{2,8}$, Norio Ozaki ${ }^{2,9}$ and Shigetoshi Kuroda ${ }^{1}$

Address: ${ }^{1}$ Department of Neuropsychiatry, Okayama University Graduate School of Medicine, Dentistry and Pharmaceutical Sciences, Okayama, Japan, ${ }^{2}$ JGIDA (Japanese Genetics Initiative for Drug Abuse), Japan, ${ }^{3}$ Institute of Neuropsychiatry, Seiwa Hospital, Tokyo, Japan, ${ }^{4}$ Department of Psychogeriatrics, National Institute of Mental Health, National Center of Neurology and Psychiatry, Kodaira, Japan, ${ }^{5}$ Department of

Neuropsychiatry, Kurume University Graduate School of Medicine, Kurume, Japan, ${ }^{6}$ Department of Psychiatry, Fujita Health University School of Medicine, Houmei, Japan, ${ }^{7}$ Department of Neuroscience, Division of Psychobiology, Tohoku University Graduate School of Medicine, Sendai, Japan, ${ }^{8}$ Department of Psychiatry, Chiba University Graduate School of Medicine, Chiba, Japan and ${ }^{9}$ Department of Psychiatry, Nagoya University Graduate School of Medicine, Nagoya, Japan

Email: Makiko Kishimoto - makiko.kishimoto@nifty.com; Hiroshi Ujike* - hujike@cc.okayama-u.ac.jp;

Yuko Okahisa - gmd15031@cc.okayama-u.ac.jp; Tatsuya Kotaka - tatsuya7kotaka7@yahoo.co.jp; Manabu Takaki - manabuta@cc.okayamau.ac.jp; Masafumi Kodama - m-kodama@cc.okayama-u.ac.jp; Toshiya Inada - han91010@rio.odn.ne.jp;

Mitsuhiko Yamada - mitsu@ncnp.go.jp; Naohisa Uchimura - naohisa@med.kurume-u.ac.jp; Nakao Iwata - nakao@fujita-hu.ac.jp;

Ichiro Sora - isora@mail.tains.tohoku.ac.jp; Masaomi Iyo - iyom@faculty.chiba-u.jp; Norio Ozaki - ozaki-n@med.nagoya-u.ac.jp;

Shigetoshi Kuroda - skuroda@cc.okayama-u.ac.jp

* Corresponding author

Published: 15 August 2008

Behavioral and Brain Functions 2008, 4:37 doi:10.1 186/1744-908I-4-37
Received: 5 August 2008

Accepted: 15 August 2008

This article is available from: http://www.behavioralandbrainfunctions.com/content/4/I/37

(C) 2008 Kishimoto et al; licensee BioMed Central Ltd.

This is an Open Access article distributed under the terms of the Creative Commons Attribution License (http://creativecommons.org/licenses/by/2.0), which permits unrestricted use, distribution, and reproduction in any medium, provided the original work is properly cited.

\begin{abstract}
Background: Frizzled 3 (Fzd3) is a receptor required for the Wnt-signaling pathway, which has been implicated in the development of the central nervous system, including synaptogenesis and structural plasticity. We previously found a significant association between the FZD3 gene and susceptibility to schizophrenia, but subsequent studies showed inconsistent findings. To understand the roles of the FZD3 gene in psychotic disorders further, it should be useful to examine FZD3 in patients with methamphetamine psychosis because the clinical features of methamphetamine psychosis are similar to those of schizophrenia.
\end{abstract}

Methods: Six SNPs of FZD3, rs3757888 in the 3' flanking region, rs9609/4 in the intron 3, rs224I802, a synonymous SNP in the exon5, rs2323019 and rs352203 in the intron 5, and rs88048I in the intron 7, were selected based on the previous schizophrenic studies and analyzed in 188 patients with methamphetamine psychosis and 240 age- and gendermatched controls.

Results: A case-control association analyses revealed that two kinds of FZD3 haplotypes showed strong associations with methamphetamine psychosis $(p<0.0000 \mathrm{I}$ ). Having the G-A-T-G or A-G-C-A haplotype of rs2241802-rs2323019rs352203-rs88048I was a potent negative risk factor (odds ratios were 0.13 and 0.086 , respectively) for methamphetamine psychosis.

Conclusion: Our present and previous findings indicate that genetic variants of the FZD3 gene affect susceptibility to two analogous but distinct dopamine-related psychoses, endogenous and substance-induced psychosis. 


\section{Background}

The neurodevelopmental hypothesis of schizophrenia suggests that interaction between genetic and environmental events occurring during critical early periods of neuronal growth may negatively influence the way by which nerve cells are laid down, differentiated, selectively culled by apoptosis and remodeled by expansion and retraction of dendrites and synaptic connections [1,2]. The Wnt family molecules play several roles in neuronal development by inducing cells to proliferate, differentiate, and survive $[3,4]$. In particular, Wnt signaling plays roles in regulating patterning during cortical development, axon remodeling, synaptic differentiation, clustering of synapsin I at presynaptic terminals [5-7] and the cytoarchitectural derangement that was observed in the brains of schizophrenics [8]. A mutation in the Wnt1 gene, one of the Wnt family genes, leads to abnormal cerebral development in mice [9], and mice deficient in Frizzled 3 (Fzd3), a receptor of Wnt ligands, showed loss of thalamo-cortical tracts and defects in corpus callosum development, abnormalities which were reported in schizophrenic patients [10-12]. Therefore, alteration of the Wnt/Fzd cascade may represent an aberrant neurodevelopment involved in schizophrenia [13].

Fzd3 is a required receptor in the Wnt-signaling pathway. In 2003, we reported a significant association between the gene encoding Fzd3 (FZD3) and susceptibility to schizophrenia [14]. Subsequent studies tried to replicate our findings, but the results were inconsistent. Yang et al. [15] revealed a significant association of the FZD3 gene with schizophrenia in Han Chinese populations by a transmission disequilibrium test, and Zhang et al. [16] also found a significant association by a family-based case-control study. On the other hand, several studies failed to find significant evidence of a genetic effect of the FZD3 gene on schizophrenia [17-19]. The inconsistencies in genetic studies in the relationship of the FZD3 gene with schizophrenia may suggest heterogeneity of schizophrenia and a requirement for further studies using larger sample size. We consider that it may be also useful to investigate the role of the FZD3 gene in other types of psychotic disorders for better understanding of the physiological roles of Fzd3 and the Wnt cascade in schizophrenia or psychotic conditions.

Repeated abuse of methamphetamine frequently predisposes to psychotic conditions. The clinical similarity between methamphetamine psychosis and schizophrenia has been pointed out, and methamphetamine psychosis has been considered to be a pharmacological model of schizophrenia, especially the paranoid subtype [20-22]. Thus, methamphetamine psychosis and schizophrenia resemble each other in a cross-section of clinical features, e.g., auditory hallucination and delusion, the longitudi- nal process of progressive exacerbation with acute relapses, good response to neuroleptics, and enduring vulnerability to relapse under stressors. Enhanced dopamine release in the striatum due to a challenge dose of methamphetamine was observed in schizophrenic patients and methamphetamine-sensitized rats, an animal model of methamphetamine psychosis [23-25]. These similarities between schizophrenia and methamphetamine psychosis in both symptomatology and pharmacological aspects may suggest that shared neural mechanisms are involved in both psychotic disorders. Therefore, in order to examine the roles of Fzd3 in mechanisms underlying the development of psychosis, we analyzed the FZD3 gene in patients with methamphetamine psychosis.

\section{Methods \\ Subjects}

The subjects consisted of 188 patients with methamphetamine psychosis (158 male, 30 female; mean age \pm SD, $36.6 \pm 11.8)$ and 240 age-, gender-, and geographical origin-matched healthy controls (192 male, 48 female; mean age \pm SD, $36.6 \pm 10.6$ ), who have no individual or family history of drug dependence or major psychotic disorders such as schizophrenia and bipolar disorders. All the subjects were unrelated Japanese, born and living in relatively restricted areas of Japan, northern Kyushu, Setouchi, Chukyo, Tokai, and Kanto. All subjects were out-patients or inpatients in psychiatric hospitals of the Japanese Genetics Initiative for Drug Abuse (JGIDA), a multicenter collaborative study group. Consensus diagnoses of methamphetamine psychosis were made by two trained psychiatrists according to the ICD-10 criteria on the basis of interviews and medical records. The patients with methamphetamine psychosis in the present study usually showed predominant positive symptoms such as delusion and hallucination. We excluded cases in which the predominant symptoms were of the negative and/or disorganized type in order to maintain the homogeneity of the patient group. The study protocol and purpose were explained to all subjects participating in the study, and written informed consent was obtained from all subjects. This study was approved by the Ethics Committee of each participating institute of JGIDA.

\section{DNA analysis}

We genotyped the three single nucleotide polymorphisms (SNPs), rs3757888 (SNP1) in the 3' flanking region, rs960914 (SNP2) in the intron 3, and rs2241802 (SNP3), a synonymous SNP in the exon5 of the FZD3 gene that were analyzed in our previous study [14]. We also analyzed three additional SNPs, rs2323019 (SNP4) and rs352203 (SNP5) in the intron 5, and rs880481 (SNP6) in the intron 7 of the gene because a significant association with schizophrenia was reported by Yang et al. [15] and Zhang et al. [16]. Genotyping was performed by the PCR- 
RFLP method. The genomic DNA was extracted from peripheral leukocytes using phenol-chloroform. Each polymorphic site was amplified by PCR (PCR primer sequence of each SNP is available on request) in a $15-\mu l$ volume containing 3\% dimethyl sulfoxide and 0.75 units of Taq DNA polymerase (Promega Co., Japan) using a unique primer set. PCR reaction was performed under the following conditions: $95^{\circ} \mathrm{C}$ for $5 \mathrm{~min}$, then 35 cycles of 30 $\mathrm{s}$ of denaturing at $95^{\circ} \mathrm{C}, 1 \mathrm{~min}$ of annealing at the appropriate temperature, and $30 \mathrm{~s}$ of extension, and final elongation at $72^{\circ} \mathrm{C}$ for $10 \mathrm{~min}$. The PCR products were digested with the corresponding restriction enzyme for each polymorphism, DdeI for rs3757888, RsaI for rs960914, AluI for rs2241802, SspI for rs2323019, NlaIII for rs352203, Eco32I for rs880481, and then electrophoresed on $3.0 \%$ agarose gels and stained with GelStar (TaKaRa Co., Japan). All genotyping was performed in a blinded fashion, with the control and cases samples mixed randomly. The genotyping of the SNPs were confirmed in part by direct sequencing or a TaqMan SNP gen- otyping assay (Applied Biosystems, Foster City, CA, U.SA.).

\section{Statistical analysis}

Statistical analysis of association was performed using SNPAlyze software (Dynacom Co., Japan). Deviation from Hardy-Weinberg equilibrium and case- control study were tested using the $\chi^{2}$ test for goodness of fit and $\chi^{2}$ test for dependence, respectively. Linkage disequilibrium (LD) was tested using the $\chi^{2}$ test, and $\mathrm{D}^{\prime}$ and $\mathrm{r}^{2}$ values were made the index in the authorization of LD. Casecontrol haplotype analysis was performed by the permutation method, and permutation $p$-values were calculated based on 100,000 replications.

\section{Results}

The genotype distribution and allele frequencies of the each polymorphism are shown in Table 1. The genotype distributions of patients and control subjects did not deviate from Hardy-Weinberg equilibrium at any SNP examined. The allele frequencies of SNP1, SNP2, and SNP3

Table I: Genotype and allele distribution of six SNPs of the FZD3 gene in controls and patients with methamphetamine (MAP) psychosis

\begin{tabular}{|c|c|c|c|c|c|c|c|c|c|}
\hline \multirow[b]{2}{*}{ SNPI } & \multirow[b]{2}{*}{ rs3757888 } & \multicolumn{4}{|c|}{ Genotype } & \multirow[t]{2}{*}{$p$} & \multicolumn{2}{|c|}{ Allele } & \multirow[t]{2}{*}{$p$} \\
\hline & & $\mathrm{N}$ & $\mathrm{A} / \mathrm{A}$ & $A / G$ & $\mathrm{G} / \mathrm{G}$ & & A & G & \\
\hline Control & & 230 & $198(86.1)$ & $31(13.5)$ & $\mathrm{I}(0.4)$ & & $427(92.8)$ & $33(7.2)$ & \\
\hline MAP Psychosis & & 186 & $151(81.2)$ & $32(7.2)$ & $3(1.6 I)$ & 0.26 & $334(89.8)$ & $38(10.2)$ & 0.19 \\
\hline SNP2 & rs960914 & $\mathrm{N}$ & $\mathrm{T} / \mathrm{T}$ & $\mathrm{T} / \mathrm{C}$ & $\mathrm{C} / \mathrm{C}$ & & $\mathrm{T}$ & C & \\
\hline Control & & 240 & $67(27.9)$ & $130(54.2)$ & $43(17.9)$ & & $264(55.0)$ & $216(45.0)$ & \\
\hline MAP Psychosis & & 185 & $45(24.3)$ & $103(55.7)$ & $37(20.0)$ & 0.66 & $193(52.2)$ & $177(47.8)$ & 0.41 \\
\hline SNP3 & rs224I802 & $\mathrm{N}$ & $\mathrm{A} / \mathrm{A}$ & $A / G$ & $\mathrm{G} / \mathrm{G}$ & & A & G & \\
\hline Control & & 240 & $49(20.4)$ & $124(5 \mid .7)$ & 67(27.9) & & $222(46.2)$ & $258(53.8)$ & \\
\hline MAP Psychosis & & 181 & $44(24.3)$ & $97(53.6)$ & $40(22.1)$ & 0.34 & $185(51.1)$ & $177(48.9)$ & 0.16 \\
\hline SNP4 & rs2323019 & $\mathrm{N}$ & $\mathrm{A} / \mathrm{A}$ & $\mathrm{A} / \mathrm{G}$ & $\mathrm{G} / \mathrm{G}$ & & $A$ & G & \\
\hline Control & & 239 & $72(31.4)$ & $113(49.3)$ & $44(19.2)$ & & $257(56.1)$ & $201(43.9)$ & \\
\hline MAP Psychosis & & 186 & $45(24.1)$ & $101(54.0)$ & $4 I(21.9)$ & 0.25 & $191((51.1)$ & $183(48.9)$ & 0.15 \\
\hline SNP5 & rs352203 & $\mathrm{N}$ & $\mathrm{T} / \mathrm{T}$ & $\mathrm{T} / \mathrm{C}$ & $\mathrm{C} / \mathrm{C}$ & & $\mathrm{T}$ & C & \\
\hline Control & & 192 & $64(33.3)$ & $98(51.1)$ & $30(15.6)$ & & $226(58.9)$ & I58(4I.I) & \\
\hline MAP Psychosis & & 176 & $49(27.8)$ & $98(55.7)$ & $29(16.5)$ & 0.52 & $196(55.7)$ & I56(44.3) & 0.38 \\
\hline SNP6 & rs88048I & $\mathrm{N}$ & $\mathrm{A} / \mathrm{A}$ & $A / G$ & $\mathrm{G} / \mathrm{G}$ & & A & G & \\
\hline Control & & 236 & $43(18.2)$ & $123(52.1)$ & $70(29.7)$ & & $209(44.3)$ & $263(55.7)$ & \\
\hline MAP Psychosis & & 186 & $30(16.1)$ & $103(55.4)$ & $53(28.5)$ & 0.97 & $163(43.8)$ & $209(56.2)$ & 0.99 \\
\hline
\end{tabular}

SNP, Single nucleotide polymorphism.

Numbers in parentheses indicate percentages. 
were approximately same as those of our previous study [14]. The allele frequencies of SNP4, SNP5, and SNP6 in the present study also showed values similar to those of previous studies of Japanese and Chinese populations [16-18].

We found no significant difference between patients and controls in the frequencies of the genotype or allele at any single SNP of the FZD3 gene. We estimated the pairwise LD between the six SNPs of the FZD3 gene using the D' and $r^{2}$ values as an index (Table 2). A D' range of 0.7-0.9 and $\mathrm{a}^{2}>0.3$ were found between SNP2, SNP3, SNP4, SNP5, and SNP6, but not between SNP1 and the other SNPs. This suggests that SNP2, SNP3, SNP4, SNP5, and SNP6 are in linkage disequilibrium and located within one LD block. Then, we performed case-control haplotype analysis using SNP2 to SNP6 (Table 3). Haplotype analyses revealed significant differences in patients and control subjects at SNP5-6, SNP4-5-6, SNP3-4-5-6, and SNP2-3-45-6, but not at SNP2-3, SNP3-4, SNP4-5, SNP2-3-4, SNP34-5, or SNP2-3-4-5. The largest $\chi^{2}$ and smallest permutation $P$ values were found in the haplotype analysis of SNP3-4-5-6 $\left(\chi^{2}=64.8\right.$, permutation $\left.p<0.00001\right)$. The estimated individual haplotypic frequencies of SNP3-4-56 are shown in Table 4. Eight kinds of haplotypes consisting of SNP3-4-5-6 with more than 1\% overall frequency were identified. The estimated haplotype frequency of GA-T-G and A-G-C-A of SNP3-4-5-6 were significantly lower in patients with methamphetamine psychosis than in controls ( $p<0.00001$ and $p=0.0003$, respectively). Conversely, the A-G-C-G haplotype was significantly in excess in patients compared with controls $(p=0.0246)$. To avoid a type I error due to multiple comparison, Bonferroni's correction was applied to the results. G-A-T-G and A-G-C-A haplotypes were still significantly less frequent in the methamphetamine patients than in the controls, but A-G-C-G was not significantly different between the groups after correction. The odds ratios G-A-T-G and A-GC-A haplotypes were 0.13 (95\%CI; 0.043-0.36) and 0.086 (95\%CI; 0.011-0.67), respectively. Accordingly, G-

Table 2: Pairwise Linkage Disequilibrium between six SNPs of the FZD3 gene

\begin{tabular}{lllllll}
\hline & SNPI & SNP2 & SNP3 & SNP4 & SNP5 & SNP6 \\
\hline SNPI & & $\mathbf{0 . 8 4 0}$ & 0.557 & 0.379 & $\mathbf{0 . 8 5 3}$ & $\mathbf{0 . 7 0 6}$ \\
SNP2 & 0.057 & & $\mathbf{0 . 7 6 0}$ & $\mathbf{0 . 9 1 5}$ & $\mathbf{0 . 9 7 0}$ & $\mathbf{0 . 7 4 9}$ \\
SNP3 & 0.031 & $\mathbf{0 . 5 3 2}$ & & $\mathbf{0 . 8 3 4}$ & $\mathbf{0 . 8 3 1}$ & $\mathbf{0 . 7 2 9}$ \\
SNP4 & 0.012 & $\mathbf{0 . 8 2 9}$ & $\mathbf{0 . 6 2 7}$ & & $\mathbf{0 . 9 8 2}$ & $\mathbf{0 . 7 6 0}$ \\
SNP5 & 0.052 & $\mathbf{0 . 8 4 1}$ & $\mathbf{0 . 5 4 2}$ & $\mathbf{0 . 8 4 3}$ & & $\mathbf{0 . 7 8 8}$ \\
SNP6 & 0.036 & $\mathbf{0 . 3 7 7}$ & $\mathbf{0 . 3 8 9}$ & $\mathbf{0 . 3 8 7}$ & $\mathbf{0 . 3 6 7}$ & \\
\hline
\end{tabular}

Linkage disequilibrium was tested using $\chi^{2}$ test. Upper right and lower left diagonals show $D^{\prime}$ and $r$-square values, respectively. $D^{\prime}>0.7$ and $r$ square $>0.3$ were shown in bold.
A-T-G and A-G-C-A haplotypes of SNP3-4-5-6 were negative risk haplotypes for methamphetamine psychosis.

\section{Discussion}

We revealed that the FZD3 gene is significantly associated with the vulnerability to psychosis induced by methamphetamine abuse, and two haplotypes of the FZD3 gene comprising SNP3-4-5-6 (rs2241802-rs2323019rs352203-rs880481) were identified as potent negative risk factors for methamphetamine psychosis. The G-A-T-G and A-G-C-A haplotypes potently reduce the risks of predisposition to psychosis after methamphetamine abuse to one seventh to one eleventh. In our previous study of schizophrenia [14], distribution of the SNP2 genotypes and haplotypes comprising SNP2-SNP3 was significantly associated with schizophrenia. Zhang et al. [16] reported that the haplotype comprising SNP4-SNP5-SNP6 was associated with schizophrenia in a Chinese population. These findings indicate that genetic variants of the FZD3 gene may affect susceptibility to two analogous but distinct psychoses, endogenous psychosis of schizophrenia and substance-induced psychosis. This may imply that Fzd3 is involved in a liability to psychotic symptoms such as hallucination and delusion irrespective of whether they are due to schizophrenia or methamphetamine psychosis.

Dopamine is a key molecule in the pathophysiology of both schizophrenia and methamphetamine psychosis. Enhanced dopamine release in the terminals of mesolimbic dopamine projections was demonstrated in vivo in patients with schizophrenia, and the amount of the increase in dopamine was positively associated with the emergence or worsening of psychotic symptoms [25]. Similar phenomena were demonstrated in mesolimbic and mesocortical terminals in animal models of methamphetamine psychosis [23]. Wnt1 was found to be expressed in close vicinity to developing midbrain dopamine neurons, which are the origins of the mesolimbic and mesocortical dopamine pathways. Wnt 1 regulates the genetic network leading to establishment of the midbrain progenitor domain in the ventral midbrain during embryonic development and of the subsequent terminal differentiation of midbrain dopamine neurons [26,27]. It is possible that differences in Wnt signaling due to genetic variants of the FZD3 gene affect the development of dopamine neurons of the mesolimbic or mesocortical pathway in early brain development and susceptibility to these two dopamine-related psychoses in adulthood.

Another molecule that potentially links Fzd3 and these two related psychoses is glycogen synthesis kinase-3 (GSK-3), a serine/threonine kinase that is a downstream component of the Wnt/Fzd cascades. Binding of Wnt ligands to Fzd family receptors leads to activation of the intracellular protein disheveled, which inactivates GSK- 
Table 3: Haplotype analysis of the FZD3 gene

\begin{tabular}{|c|c|c|c|c|c|}
\hline & ISNP & $2 S N P$ & $3 S N P$ & 4SNP & 5SNP \\
\hline SNP ID & & & Permutation $\mathrm{p}$-value & & \\
\hline SNP2 & 0.41 & & & & \\
\hline (rs9609|4T>C) & & 0.16 & & & \\
\hline SNP3 & 0.16 & & 0.22 & & \\
\hline$(r s 224 \mid 802 G>A)$ & & 0.15 & & 0.35 & \\
\hline SNP4 & 0.15 & & 0.15 & & $<0.00001$ \\
\hline$(\mathrm{rs} 23230 \mid 9 A>G)$ & & 0.072 & & $<0.00001$ & \\
\hline SNP5 & 0.38 & & 0.00001 & & \\
\hline$(r s 352203 T>C)$ & & 0.00002 & & & \\
\hline $\begin{array}{c}\text { SNP6 } \\
(\mathrm{rs} 88048 \mid \mathrm{A}>\mathrm{G})\end{array}$ & 0.99 & & & & \\
\hline
\end{tabular}

Haplotype analysis was performed by permutaion method. Bold values represent significant $\mathrm{p}$ values.

$3 \beta$. This in turn leads to the stabilization and accumulation of $\beta$-catenin, which translocates to the nucleus where it interacts with nuclear transcription factors for the genes involved in neuronal development. Briefly, GSK-3 $\beta$ mediates Wnt/Fzd signaling cascades. Dysregulation of GSK-3 $\beta$ and $3 \alpha$ is one of promising neurodevelopmental hypotheses of schizophrenia $[13,28]$. GSK-3 is also regulated by dopamine signaling through protein kinase B [29]. Several studies showed, but not consistently, that GSK-3 protein levels and activities are altered in schizophrenic brains [30,31] and lymphocytes [32,33]. Several genes, e.g., DISC1 and NRG1, which have been repeatedly shown to be associated with susceptibility to schizophrenia, are involved in GSK-3/Wnt regulatory pathways [28]. Recently, the gene encoding DKK4, a component of the GSK-3/Wnt signaling cascade, was shown to be associated with schizophrenia. DKK4 inhibits Wnt-Fzd binding, resulting in inactivation of GSK-3 [34]. On the other hand, amphetamine also affects GSK-3 activity. Administration of amphetamine to mice increased Ser9 phosphorylation of GSK-3 $\beta$, resulting in a reduction of its activity in the frontal cortex and striatum [35], and GSK-3 gene knockdown mice showed a reduced response to amphet- amine [36]. Intriguingly, psychotomimetics of two different classes, phencyclidine and D-lysergic acid, also had the same effects on GSK-3 $\beta$, which may imply that substance-induced psychosis might be the result of a reduction in GSK-3 signaling. In contrast, chronic treatment with typical and atypical neuroleptics that ameliorate the psychotic symptoms of schizophrenia and methamphetamine psychosis increase the levels and activities of GSK-3 [37]. It was also found that chronic neuroleptic treatment increased $\beta$-catenin in the ventral midbrain, whereas amphetamine decreased it [38]. These findings indicate that the altered GSK-3/Wnt signaling is involved in liability to expression of positive psychotic symptoms such as the hallucinations and delusions in patients suffering from both schizophrenia and methamphetamineinduced psychosis. This hypothesis may be supported by our present and previous findings because the FZD3 gene was significantly associated with not only schizophrenia but also methamphetamine psychosis.

The present results were still significant even after a Bonferroni correction, although it is possibly a chance finding due to less power. The power analysis showed that our

Table 4: Haplotype frequencies from positive permutation analyses

\begin{tabular}{ccccc}
\hline Haplotype & \multicolumn{2}{c}{ Frequency } & Permutation p-values & Odds ratio $(95 \% \mathrm{Cl})$ \\
\cline { 1 - 2 }$($ SNP3-4-5-6) & Controls & MAP Psychosis & & \\
G-A-T-A & 0.3523 & 0.4148 & 0.0889 & $1.42(1.14-1.76)$ \\
A-G-C-G & 0.3178 & 0.3970 & 0.0246 & $0.13(0.07-0.22)$ \\
G-A-T-G & 0.1542 & 0.0243 & 0.00001 & $0.086(0.03-0.24)$ \\
A-A-T-G & 0.0382 & 0.0635 & 0.1283 & 0.0003 \\
A-G-C-A & 0.0625 & 0.0070 & 0.2791 & 0.1678 \\
A-G-T-G & 0.0211 & 0.0354 & 0.4565 & \\
G-G-C-G & 0.0196 & 0.0379 & 0.0090 & \\
A-A-T-A & 0.0169 & & \\
\hline
\end{tabular}

Haplotypes with overall frequencies are less than I\% were eliminated. 
present sample size had more than $80 \%$ power to detect a significant difference at 0.05 of any SNP examined, but it must have less power for haplotype analyses. Therefore, our findings should be confirmed in studies using a larger number of subjects and different populations. It may also be useful for further investigation of the roles of Fzd3 in psychoses to examine the genetic association of the FZD3 gene with other types of psychoses, e.g., cocaine-induced paranoia or delusional type of bipolar disorders.

\section{Conclusion}

We examined genetic association of FZD3 and found that two kinds of FZD3 haplotypes showed strong associations with methamphetamine psychosis. Having the G-A-T-G or A-G-C-A haplotype of rs2241802-rs2323019rs352203-rs880481 was a potent negative risk factor (odds ratios were $0.13(95 \% \mathrm{CI} ; 0.07-0.22)$ and 0.086 (0.03-0.24), respectively) for methamphetamine psychosis. Our present and previous findings indicate that genetic variants of the FZD3 gene affect susceptibility to two analogous but distinct dopamine-related psychoses, endogenous and substance-induced psychosis.

\section{Competing interests}

The authors declare that they have no competing interests.

\section{Authors' contributions}

HU conceived of the study, reviewed the manuscript and supervised all management, analysis, and interpretation of the data. MKi, YO, TK supervised by MT and MKo, genotyped samples and analyzed data, and MKi drafted manuscript and produced all tables. HU organized collaboration of Japanese substance abuse group, and HU, TI, MY, NU, NI, IS and NO collected genome samples and informed consents. HU and SK managed research expense. All authors read and approved for final manuscript.

\section{Acknowledgements}

We thank the Zikei Institute of Psychiatry (Okayama, Japan) and the Ministry of Health, Labor, and Welfare of Japan.

\section{References}

I. Bloom FE: Advancing a neurodevelopmental origin for schizophrenia. Arch Gen Psychiatry 1993, 50:224-227.

2. Weinberger DR: Implications of normal brain development for the pathogenesis of schizophrenia. Arch Gen Psychiatry 1987, 44:660-669.

3. Nusse R, Varmus HE: Wnt genes. Cell 1992, 69:1073-1087.

4. Parr BA, McMahon AP: Wnt genes and vertebrate development. Curr Opin Genet Dev 1994, 4:523-528.

5. Grove EA, Tole S, Limon J, Yip L, Ragsdale CW: The hem of the embryonic cerebral cortex is defined by the expression of multiple Wnt genes and is compromised in Gli3-deficient mice. Development 1998, 125:2315-2325.

6. Hall AC, Lucas FR, Salinas PC: Axonal remodeling and synaptic differentiation in the cerebellum is regulated by WNT-7a signaling. Cell 2000, 100:525-535.
7. Lucas FR, Salinas PC: WNT-7a induces axonal remodeling and increases synapsin I levels in cerebellar neurons. Dev Biol I 997, 192:3I-44.

8. Cotter D, Kerwin R, al-Sarraji S, Brion JP, Chadwich A, Lovestone S, Anderton $B$, Everall I: Abnormalities of Wnt signalling in schizophrenia-evidence for neurodevelopmental abnormality. Neuroreport 1998, 9:1379-1383.

9. McMahon AP, Bradley A: The Wnt-I (int-I) proto-oncogene is required for development of a large region of the mouse brain. Cell 1990, 62:1073-1085.

10. Wang Y, Thekdi N, Smallwood PM, Macke JP, Nathans J: Frizzled-3 is required for the development of major fiber tracts in the rostral CNS. J Neurosci 2002, 22:8563-8573.

11. Diwadkar VA, DeBellis MD, Sweeney JA, Pettegrew JW, Keshavan MS: Abnormalities in MRI-measured signal intensity in the corpus callosum in schizophrenia. Schizophr Res 2004, 67:277-282.

I2. Ananth H, Popescu I, Critchley HD, Good CD, Frackowiak RS, Dolan $\mathrm{RJ}$ : Cortical and subcortical gray matter abnormalities in schizophrenia determined through structural magnetic resonance imaging with optimized volumetric voxel-based morphometry. Am J Psychiatry 2002, 159: I 497-I 505.

13. Kozlovsky N, Belmaker RH, Agam G: GSK-3 and the neurodevelopmental hypothesis of schizophrenia. Eur Neuropsychopharmacol 2002, I 2: 13-25.

14. Katsu T, Ujike H, Nakano T, Tanaka Y, Nomura A, Nakata K, Takaki M, Sakai A, Uchida N, Imamura T, Kuroda S: The human frizzled3 (FZD3) gene on chromosome 8p2I, a receptor gene for Wnt ligands, is associated with the susceptibility to schizophrenia. Neurosci Lett 2003, 353:53-56.

15. Yang J, Si T, Ling Y, Ruan Y, Han Y, Wang X, Zhang H, Kong Q, Li X, Liu C, Zhang D, Zhou M, Yu Y, Liu S, Shu L, Ma D, Wei J: Association study of the human FZD3 locus with schizophrenia. Biol Psychiatry 2003, 54:1298-1301.

16. Zhang Y, Yu X, Yuan Y, Ling Y, Ruan Y, Si T, Lu T, Wu S, Gong X, Zhu Z, Yang J, Wang F, Zhang D: Positive association of the human frizzled 3 (FZD3) gene haplotype with schizophrenia in Chinese Han population. Am J Med Genet B Neuropsychiatr Genet 2004, I 29B(I):16-19.

17. Hashimoto R, Suzuki T, Iwata N, Yamanouchi Y, Kitajima T, Kosuga A, Tatsumi M, Ozaki N, Kamijima K, Kunugi H: Association study of the frizzled-3 (FZD3) gene with schizophrenia and mood disorders. J Neural Transm 2005, I I 2:303-307.

18. Ide M, Muratake T, Yamada K, Iwayama-Shigeno Y, Iwamoto K, Takao $\mathrm{H}$, Toyota T, Kaneko N, Minabe Y, Nakamura K, Kato T, Mori N, Asada T, Someya T, Yoshikawa T: Genetic and expression analyses of FZD3 in schizophrenia. Biol Psychiatry 2004, 56:462-465.

19. Wei J, Hemmings GP: Lack of a genetic association between the frizzled-3 gene and schizophrenia in a British population. Neurosci Lett 2004, 366:336-338.

20. Sato M: A lasting vulnerability to psychosis in patients with previous methamphetamine psychosis. Ann N Y Acad Sci 1992, 654:160-170.

21. Ujike H, Sato M: Clinical features of sensitization to methamphetamine observed in patients with methamphetamine dependence and psychosis. Ann N Y Acad Sci 2004, 1025:279-287.

22. Snyder SH: Amphetamine psychosis: a "model" schizophrenia mediated by catecholamines. Am J Psychiatry 1973, 130:6 1-67.

23. Ujike $\mathrm{H}$ : Stimulant-induced psychosis and schizophrenia: the role of sensitization. Curr Psychiatry Rep 2002, 4: I77-I84.

24. Kazahaya Y, Akimoto K, Otsuki S: Subchronic methamphetamine treatment enhances methamphetamine- or cocaineinduced dopamine efflux in vivo. Biol Psychiatry 1989, 25:903-9/2.

25. Laruelle M, Abi-Dargham A, van Dyck CH, Gil R, D'Souza CD, Erdos J. McCance E, Rosenblatt W, Fingado C, Zoghbi SS, Baldwin RM, Seibyl JP, Krystal JH, Charney DS, Innis RB: Single photon emission computerized tomography imaging of amphetamineinduced dopamine release in drug-free schizophrenic subjects. Proc Natl Acad Sci USA 1996, 93:9235-9240.

26. Prakash N, Brodski C, Naserke T, Puelles E, Gogoi R, Hall A, Panhuysen M, Echevarria D, Sussel L, Weisenhorn DM, Martinez S, Arenas E, Simeone A, Wurst W: A Wnt I-regulated genetic network controls the identity and fate of midbrain-dopaminergic progenitors in vivo. Development 2006, 133:89-98. 
27. Panhuysen M, Vogt Weisenhorn DM, Blanquet V, Brodski C, Heinzmann $U$, Beisker W, Wurst W: Effects of Wnt I signaling on proliferation in the developing mid-/hindbrain region. Mol Cell Neurosci 2004, 26: I0I-III.

28. Lovestone S, Killick R, Di Forti M, Murray R: Schizophrenia as a GSK-3 dysregulation disorder. Trends Neurosci 2007, 30:142-149.

29. Bibb JA: Decoding dopamine signaling. Cell 2005, I 22:153-155.

30. Emamian ES, Hall D, Birnbaum MJ, Karayiorgou M, Gogos JA: Convergent evidence for impaired AKTI-GSK3beta signaling in schizophrenia. Nat Genet 2004, 36: 131-137.

3I. Beasley C, Cotter D, Khan N, Pollard C, Sheppard P, Varndell I, Lovestone S, Anderton B, Everall I: Glycogen synthase kinase-3beta immunoreactivity is reduced in the prefrontal cortex in schizophrenia. Neurosci Lett 2001, 302:117-120.

32. Yang SD, Yu JS, Lee TT, Yang CC, Ni MH, Yang YY: Dysfunction of protein kinase FA/GSK-3 alpha in lymphocytes of patients with schizophrenic disorder. / Cell Biochem 1995, 59: I08-II6.

33. Nadri C, Kozlovsky N, Agam G, Bersudsky Y: GSK-3 parameters in lymphocytes of schizophrenic patients. Psychiatry Res 2002, I I 2:5।-57.

34. Proitsi P, Li T, Hamilton G, Di Forti M, Collier D, Killick R, Chen R, Sham P, Murray R, Powell J, Lovestone S: Positional pathway screen of wnt signaling genes in schizophrenia: association with DKK4. Biol Psychiatry 2008, 63:13-16.

35. Svenningsson P, Tzavara ET, Carruthers R, Rachleff I, Wattler S, Nehls M, McKinzie DL, Fienberg AA, Nomikos GG, Greengard P: Diverse psychotomimetics act through a common signaling pathway. Science 2003, 302:14|2-14|5.

36. Beaulieu JM, Sotnikova TD, Yao WD, Kockeritz L, Woodgett JR, Gainetdinov RR, Caron MG: Lithium antagonizes dopaminedependent behaviors mediated by an AKT/glycogen synthase kinase 3 signaling cascade. Proc Natl Acad Sci USA 2004, 101:5099-5104.

37. Kozlovsky N, Amar S, Belmaker RH, Agam G: Psychotropic drugs affect Ser9-phosphorylated GSK-3 beta protein levels in rodent frontal cortex. Int I Neuropsychopharmacol 2006, 9:337-342.

38. Alimohamad H, Sutton L, Mouyal J, Rajakumar N, Rushlow W]: The effects of antipsychotics on beta-catenin, glycogen synthase kinase- 3 and dishevelled in the ventral midbrain of rats. J Neurochem 2005, 95:5।3-525.

Publish with Bio Med Central and every scientist can read your work free of charge

"BioMed Central will be the most significant development for disseminating the results of biomedical research in our lifetime. "

Sir Paul Nurse, Cancer Research UK

Your research papers will be:

- available free of charge to the entire biomedical community

- peer reviewed and published immediately upon acceptance

- cited in PubMed and archived on PubMed Central

- yours - you keep the copyright

Submit your manuscript here:

http://www.biomedcentral.com/info/publishing_adv.asp
BioMedcentral 